\begin{tabular}{|c|c|c|c|}
\hline & & Fett & Protein \\
\hline Erdnuf3 & . & $48,86 \%$ & $32,41^{\circ} \%$ \\
\hline Paranuk . . . . . . & & 62,73 & 16,20, \\
\hline Haselnue (Giovanni) . & & 56,04, & 15,44, \\
\hline$" \quad$ (Neapolitaner) & & 60,22, & 15,44, \\
\hline WaInu范 (deutsche) . . & & 56,78, & 19.49, \\
\hline$" \quad$ (französische) & & 60,71, & 17,63, \\
\hline
\end{tabular}

Die Berechnung auf Trockensubstanz, die eine einwandfreie Vergleichung vorstehender Zahlenwerte gestatten würde, hat anscheinend nicht stattgefunden.

E. Dinslage.

E. Scholl: Die Reindarstellung des Chitins a us Boletus edulis. (Monatsh. f. Chemie 1908, 29, 1029-1036.) - Durch abwechselndes Auskochen der fein gepulverten Fruehtkörper von Boletus edulis mit Wasser und 10\%-iger Kalilauge, unter Aussehluß von Säuren oder heftig wirkenden Oxydationsmitteln, hat Verf. reines Chitin dargestellt. Die Ausbeute betrug 5 bis 6\% vom Gewicht der lufttrockenen Pilze. Das gewonnene Chitin verhielt sich genau wie tierisches Chitin, es ist in konzentrierten Alkalien vollkommen unlöslich, wird dagegen von Säuren unter Hydrolyse leicht angegriffen. Bei der Hydrolyse mit Salzsäure entsteht salzsaures Glucosamin, das sich aus der konzentrierten Lösung sofort in Krystallen (Ausbeute 78\%) ausscheidet; diese Krystalle lassen sich aus einigen Centigrammen Chitin mikrochemisch erhalten. Die Membranen von Boletus edulis bestehen demnach der Hauptmasse nach aus reinem Chitin.

G. Sonntag.

\title{
Kaffee, Kakao, Tee.
}

C. Kippenberger: Neue Hinweise zur Gewinnung coffein-bezw. tein armer Lebensmittel, nebst Erörterungen zum Patentgesetz vom 7. A pril 1891. (Zeitschr, angew. Chem. 1909, 22, 1837-1841.) - Nachdem Verf. sich einleitend im allgemeinen über die Wirkung alkaloidhaltiger Genußmittel ausgesprochen und die Herstellung coffeinfreien Kaffees in den Grundzügen angedeutet hat, beschreibt er ein von ihm erfundenes neues Verfahren zur Gewinnung coffeinfreien Kaffees bezw. teinfreien Tees. Er hatte dasselbe zum Patent angemeldet, zog jedoch die Patentanmeldung zurück, nachdem ihm bedeutet wurde, daß das von ihm verwendete Extraktionsmittel teilweise bereits in einer französischen Patentsehrift genannt wird. Die Erfindung beruht auf der Beobachtung, daß Coffein und Tein aus den in Betracht kommenden Nahrungs- und Genußmitteln, wie Kaffee und Tee, durch Behandlung mit erwärmten fetten Ölen (Glyceriden) einerseits und durch Glycerin, auch Aceton andererseits ausziehbar ist. Es hat sich nämlich gezeigt: 1. daß Coffein in Ol von Zimmertemperatur so gut wie unlöslich, in heißem Öl jedoch in ganz ungewöhnlich großen Mengen löslich ist, sodaß beim Erkalten der warmen Lösung von Coffein in Öl eine Suspension in dem Sinne eintreten kann, daß eine pastenartige Masse entsteht; 2. daß Coffeintannat, das in Äther, Benzol, Chloroform, Wasser so gut wie unlöslich ist, auch von ammoniakhaltigem Wasser nur schwer angegriffen wird, von Glycerin leicht und vollständig gelöst und auch durch Aceton in Lösung übergeführt werden kann. Das Verfahren denkt sich Verf. folgendermaßen: Der rohe Kaffee wird als solcher oder nach der Behandlung in technisch bekanntem Sinne, wie Anrösten, Behandlung mit Dampf (Aufschließen), mit fetten Ölen (Glyceriden) bei Temperaturen und unter Druckverhältnissen hehandelt, bei welchen die Glyceride unzersetzt bleiben. Nach zweckentsprechender Zeit werden die Bohnen von der Flüssigkeit wieder befreit. Die Trennung der Flüssigkeit vom Kaffee könnte in Zentrifugen oder auf irgend eine andere mechanische Weise erfolgen. Die Befreiung der Öle von Coffein erfolgt durch Erkaltenlassen der Lösung oder durch Ausschütteln 
mit Wasser oder anderen für Coffein bekannten Lösungsmitteln, sodaf das Öl beständig zurückgewonnen wird. Um einem solchen Kaffee auch das an Gerbstoff gebundene Coffein teilweise oder ganz zu entziehen, kann derselbe noch entweder mit Glycerin oder mit Aceton oder mit beiden Lösungsmitteln in ähnlicher Weise wie mit Öl behandelt werden. Aus den Untersuchungen des Verf.'s geht ferner hervor, daß die Glyceride exsetzt werden können durch ganze Gruppen anderer, im allgemeinen indifferenter und bisher als Coffeinlösungsmittel in der Literatur nicht erwähnter Körper, sofern dieselben einen. Siede- oder Schmelzpunkt über $100^{\circ}$, am besten über $150^{\circ}$ besitzen. Es ist eine bislang unbeobachtete Eigenschaft des Coffeins, daß dasselbe vornehmlich bei Temperaturen von $100-200^{\circ}$ mit den angedeuteten indifferenten Körpern ein homogenes Gemenge (klare Lösung verhältnismäßig groß̊er Mengen Coffeins) gibt. Als solche indifferente Körper werden geuannt: Kohlenwasserstoffe der Fettreihe, einzeln für sich wie in Gemengen, z. B. Paraffin; ebenso Kohlenwasserstoffe der aromatischen Reihe und deren Derivate, vornehmlich deren Alkyl- und Halogenderivate. Ferner sind hervorzuheben: höhere Alkohole und Äther, auch Ester, wie Amylalkohol, Amyläther und Acetessigester. Zur Entfernung des Coffeins aus Kaffeebohnen können jedoch nur solche Körper in Betracht kommen, die sich möglichst wieder entfernen lassen. Keiner der genannten Körper ist aber so gut dazu geeignet wie die Glyceride. Die Behandlung der Kaffeebohnen mit fetten Olen führt nach dem Verf. nicht nur zu einem coffeinarmen Produkt, sondern wirkt auch verbessernd auf den Geschmack des gerösteten Kaffees, was wohl daher rühren mag, daß OI die für den Geschmack des Kaffees wesentlichen Bestandteile nicht extrahiert.

P. W. Neumann.

S. Gliicksmann und C. Gérini: Einige Untersuchungen über die physiologische Wirkung von koffeinfreiem Kaffee. (Besondere Schrift, 8 Seiten.) - Verff. kommen in ibren Untersuchungen über koffeinfreien Kaffee zu nachstehenden SchluBfolgerungen: Der Blutdruck wird nur durch den Genuß sehr großer Mengen beeinfluBt. Die Stickstoffausscheidung durch den Harn ist im allgemeinen leicht vergrößert, was durch den geringen Gehalt des koffeinarmen Kaffees an Koffein zu erklären ist. Die schädigenden Wirkungen des gewöhnlichen Kaffees werden also bei koffeinfreiem Kaffee stark vermindert. Der Geschmack des koffeinfreien Kaffees ist ziemlich angenehm, aber weniger aromatisch und etwas bitterer als der des gewöhnlichen Kaffees derselben Qualität.

J. Clement.

C. Hartwich und P.A. Du Pasquier: Beiträge zur Kenntnis des Tees. (Apoth.Ztg. 1909, 24, 109-110, 119-121, 130-131 und 136-137.) - Die Frage des mikrochemischen Coffeinnachweises in der pflanzlichen Zelle hat bisher keine befriedigende Lösung gefunden. Unter den verschiedenen auf ihre Gebrauchsfähigkeit geprüften Reaktionen ist diejenige mit Goldchlorid noch die beste, wenn ihr auch völlige Zuverlässigkeit und Sicherheit fehlen. Denn einerseits erwies sich der mit Goldchlorid im Teeblatte erzeugte braune Niederschlag nicht der Erwartung gemäß als krystallin und andererseits lieferte der Tee-Gerbstoff die gleiche Reaktion. Nach 15-20 Minuten langem Wässern der mikroskopischen Schnitte, wodurch der Gerbstoff bis zum Verschwinden der Eisenchloridreaktion herausgelöst wurde, trat der als Coffeingoldchlorid angesprochene braune Niederschlag in die Erscheinung und zwar im Mesophyll, nicht in der Epidermis, Bei den ebenso behandelten Schnitten des Stammes und der Wurzel des Teestrauches gelang die Reaktion nicht, was durch die nur geringen, quantitativ bestimmten Coffeinmengen erklärlich wird. Uberhaupt zeigten die grünen, assimilierenden Pflanzenteile den höchsten Coffeingehalt, z. B die grünen Sprosse acht Wochen alter Keimlinge $1,6 \%$, die Keimwurzeln dagegen $0,18 \%$. Obgleich Teeblätter bei fortschreitendem Wachstum prozentual bedeutend an Coffein abnehmen, nimmt der absolute Gehalt zu. Ganz im Gegensatz zu der Behauptung anderer Autoren, daß vom Tee- 
strauch abgefallene Blätter kein Coffein enthalten, fanden die Verff. hierin, wenn auch prozentual einen niedrigen, so doch absolut den böchsten Gehalt. Als Baustein für das pflanzliche Protein kann das Coffein nicht in Frage kommen. $\mathrm{Zu}$ seiner Bestimmung erwies sich die Methode von C. C. Keller als nicht empfehlenswert, da sie vielfach ein unreines Produkt und bedeutend böhere als die aus dem Stickstoffgehalte berechneten Werte lieferte. Freies und gebundenes Coffein wurde durch Chloroformextraktion der Blätter vor und nach Zugabe von Ammoniak gewonnen. Besonderes Augenmerk mul auf das Trocknen des abgeschiedenen Coffeins gerichtet werden. Denn ein mehrere Stunden im Wassertrockenschrank erhitztes Coffein, das aus wässeriger Lösung erhalten war, zeigte bei wejterem Erbitzen auf $97-99^{\circ}$ eine fortdauernde und fast konstante Abnahme von stündlich $0,4 \%$ des Gesamtgewichts, welche Beobachtung mit derjenigen Pukner's (1905), der einen stündlichen Verlust von $0,3 \%$ feststellte, ziemlich übereinstimmt. Daher schlagen Verff. Trocknen über Schwefelsäure vor. Der Tee-Gerbstoff, zu dessen Bestimmung sich mit gutem Erfolge die Kupferacetatmethode von Fleck eignet, zeigt mindestens teilweise glykosidischen Charakter. Beim Passieren der verschiedenen Stadien der Teeherstellung aus frischen Blättern zeigte sich folgendes Bild:

\begin{tabular}{c} 
Bezeichnung \\
\hline
\end{tabular}

Die bei dem Tee aus Pavia in Klammern gesetzten beiden Zahlen sind nicht direkt gefunden, sondern berechnet nach dem in einer großen Anzahl von Mustern fertigen Tees ermittelten Verhältnis zwischen freiem und gebundenem Coffein von $3: 1$. Die Hauptmenge des Coffeins wird beim Welken und Rollen in Freiheit gesetzt, während der gleichzeitig abgespaltene Gerbstoff zum Teil intakt bleibt und erst beim Fermentieren Phlobaphen liefert, was an der roten Farbe der Blätter zu erkennen ist. Versuche, bei denen die Fermentation im Kohlensäurestrom vorgenommen wurde, lieferten das Ergebnis, daß dem Luftsauerstoff nur bezüglich der Zersetzung des Gerbstoffes eine gewisse Bedeutung zuzuschreiben ist. Ferner wurde festgestellt, daß keinesfalls Mikroorganismen, sondern vermutlich Fermente Träger der Fermentationswirkung sind. Auf die Beschreibung und Analyse von 19 verschiedenen, zum Teil selteneren Teesorten sei besonders verwiesen. - Im Hinblick auf die in der neneren Literatur zum Ausdruck kowmenden Gesichtspunkte bezüglich der Coffeinbestimmung dürfte die Arbeit zur Nachprüfung anregen.

A. Dinslage.

G. Halphen: A nalys e der Ka ka obutter. (Annal. Chim. analyt. 1909, 14, 254-256.) Vergl. Z. 1909, 18, 439.

\section{Patente.}

Dr. Emilio de Mattia in Recoaro (Italien) und Giacomo de Mattia in San Paulo (Brasilien): Verfahren zam Rösten von Kaffee. D.R.P. 211151 vom 28. Novbr. 1906. (Patentbl. 1909, 30, 1721.) - Das Verfahren bezweckt die Erkennung des Endpunktes der Röstung von Kaffee und besteht darin, daß̉ die aus den Bohnen während des Röstprozesses 
sich entwickelnden Gase durch zwei Wo ulff'sche Flaschen geleitet werden, in deren zweiter sich eine Lösung von durch schweflige Säure entfärbtem Fuchsin im Verhältnis von 0,25 zu 1000 Teilen Wasser befindet. Das Verfahren gestaltet sich im einzelnen, wie folgt: Zum Rösten wird eine geschlossene drehbare Trommel oder - was besonders zweckmä̈ig ist ein kugelförmiger Röster benutzt, dessen Achse hohl ist, damit die Röstgase auf diesem Wege entweichen können. An die hoble Achse werden nacheinander zwei Woulff'sche Flaschen angeschlossen, deren erste mit Wasser and deren zweite mit einer durch schweflige Saure entfärbten Lösung von $0,25 \mathrm{~g}$ Fuchsin zu $1000 \mathrm{~g}$ Wasser gefüllt ist. Die zweite Flasche stebt mit einem Aspirator in Verbindung, welcher den Durchtritt der Röstgase erleichtert. Die erste Flasche dient dazu, die während des Röstprozesses sich bildenden Pyridınverbinaungen aufzunehmen, während der Jnhalt der zweiten dazu dient, mit dem Eintreten der Violettfärbung den Zeitpunkt der vollendeten Röstung anzuzeigen.

Ludwig Seifer in München: Verfahren zur Konservierung des Aromas von Kaffee. D.R.P. 209267 vom 14. Februar 1906. (Patentbl. 1909, 30, 1297.) - Nach vorliegendem Verfahren werden unter Ausschluf aller Konservierungsmittel die Aromastoffe des Kaffeess lange Zeit erhalten. Man füllt zu diesem Zweck den Kaffee unmittelbar nach der Röstung in Blechdosen, Gläser oder sonstige Verpackungsgefäße ab, verschließst diese luftdicht und erhitzt zweckmäkig im Autoklaven auf $60-70^{\circ}$. Um die Berührung mit dex Hand vollständig auszuschalten, 1ällt der geröstete Kaffee zweckmäf g nach dem Abkühlen unmittelbar von der Röstmaschine äber eine autoratische Wäge- und Abfüllvorrichtang in die Versand. gefäße.

M. Sehiitz.

\section{Wein.}

J. Laborde: Über die Umwandlung der chromogenen Substanz der Trauben während der Reife. (Compt. rend. 1908, 147, 753-755.) - Bei dem Versuche, die Gesamtmenge der in den grünen Schalen enthaltenen tanninartigen, chromogenen Stoffe zu bestimmen (vergl. Z. 1910, 19, 496), stellte Verf. zwei Formen dieser Stoffe fest, eine in starkem Alkohol lösliche und eine in größerer Menge vorhandene unlösliche. Während des Reifens geht die unlösliche Form allmählich in die lösliche über; zugleich entwickelt sich bei den roten Trauben der Farbstoff und man bemerkt eine gewisse, bei den weißen Trauben stärker als bei den roten Trauben hervortretende Abnahme der Gesamtmenge der chromogenen Substanz. Die roten Trauben enthalten zu Beginn der Reife im löslichen Anteil Farbstoff und unverändertes Önotannin. Nach vollendeter Reife sind diese Unterschiede nicht mehr vorhanden oder viel geringer. In den Schalen der völlig reifen weißen Trauben ist nicht nur die Gesamtmenge chromogener Substanz verringert, sondern der lösliche Teil liefert auch im Autoklaven nur noch unlöslichen, braunen Farbstoff wie stark oxydierte Lösungen von Önotannin. Das Löslichwerden der Reserve-Gerbstoffe bei weißen und roten Trauben ist wahrscheinlich die Wirkung eines Enzyms. Ob die Umwandlung des Önotannins in Farbstoff bei den roten Trauben ebenfalls durch ein Enzym, das den weißen Trauben fehlt, bewirkt wird, konnte nicht festgestellt werden.

G. Sonntag.

Ph. Malvezin: Über den Ursprung der Farbe der roten Trauben. (Compt. rend. 1908, 147, 384-386.) - Im Anschluß an die Versuche von L a borde (vergl. das vorstehende Referat) hat Verf. einige grüne Kerne von roten Medoctrauben in einem offenen Kolben mit Wasser auf $85^{\circ}$ erhitzt. Nach 17 Stunden war die Flüssigkeit gelb, nach 24 Stunden schön weinrot geworden. Wenn das Erhitzen bei Luftabschluß im zugeschmolzenen Gefäß stattfand, so wurde die Flüssigkeit auch in längerem Zeitraum nur gelb, nahm aber nach dem Öffnen des Gefäßes bei weiterem Erwärmen ebenfalls allmählich die weinrote Farbe an. Mit Kernen von weißer Muskatellertraube wurde die gleiche Färbung erzielt. Weinblätter und Ranken gaben nur gelbe Färbung. Verf. nimmt das Vorhandensein einer einzigen chromogenen Substanz an, die sich unter gleichzeitigem EinfluB der Luft, der Wärme und vielleicht auch des Lichtes umwandelt, in der Natur unter denselben Bedingungen 